\title{
32
}

\section{Scientific evaluation of law's effects on public health}

\author{
Scott Burris
}

\section{Introduction}

Law has played an indispensable role in improving public health over the past 100 years. Laws and legal practices also have significant unintended effects on health. Just as in other realms of regulation, however, it is not enough to assert the important roles of law in public health. If law matters to public health, we have to be able to show how, under what circumstances and to what degree. We have to produce evidence. Public health law research (PHLR) is the field devoted to creating and disseminating that evidence.

This chapter describes scientific theory and methods for investigating the development, implementation and effects of public health laws, enforcement strategies and other basic forms of regulation. Part one is an introduction to the basic concepts of PHLR. Part two is devoted to special questions of measurement that arise when law is the independent variable, and describes new tools for measuring law. Part three describes theories that researchers from diverse disciplines can use to study how law influences behaviour-the mechanisms or processes through which a rule manages to have measurable effects on health. Finally, part four considers the various study designs for PHLR. 


\section{Law, health and science}

Public health law research (also referred to as 'legal epidemiology') is the scientific study of the relation of law and legal practices to population health (Burris et al. 2010, 2016). This includes both direct relationships between law and health and relationships mediated through the impacts of law on health behaviours and other processes and structures that affect population health. Both 'law' and 'health' are broadly conceived in PHLR.

Consistent with the general approach in studies of regulation and governance (Braithwaite et al. 2007), PHLR's conception of 'law' is not confined to 'law on the books'-constitutions, statutes, judicial opinions, and so on. PHLR is necessarily concerned with the psychosocial mechanisms through which compliance is achieved, the range of state and non-state regulatory techniques that may be deployed and how law operates as a social practice embedded in institutions and implemented by agents (Stryker 2013). It is part of, not distinct from, the social environment whose influence on health is the focus of social epidemiology.

In the tradition of social epidemiology, health is understood as a product of the interaction of genes, people and places, and not simply, or even primarily, a consequence of consuming healthcare services (Berkman and Kawachi 2000). Most things human beings do, and most characteristics of our environments, have some impact on the level and distribution of health in a population (CSDH 2008).

This view of law and epidemiology suggests two broad roles for law in the production of health. First, law helps build and maintain the social, economic and physical worlds in which we live, learn, work and play. It authorises, structures and protects institutions and statuses, validating and protecting current distributions of power and resources and prescribing methods for change. Second, law acts as a mechanism through which social structures are transformed into a level and distribution of health in a population. The life course of a person with the status 'poor', for example, will often be shaped by experiences with legal rules, institutions and agents that are quite different from those of better-off people (Sarat 1990). 


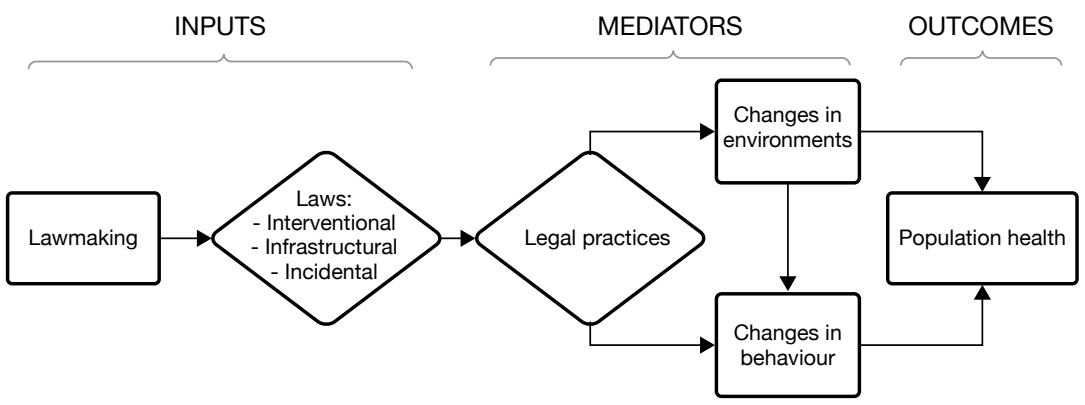

Figure 32.1 Logic model of public health law research

Source: Author's work.

The spectrum of PHLR studies is depicted in Figure 32.1. Moving from left to right, we begin with studies of the lawmaking process, observing and analysing the factors that influence which laws are enacted and that shape the specific characteristics of the statutes and regulations adopted. In these studies, public health laws themselves are the outcome of interest and political and other factors are the explanatory variables. Next, studies of legal practices focus on the implementation of the law on the books, including how the law affects the structure or operation of regulatory systems. The completeness of implementation and the effectiveness of mechanisms for ensuring compliance with the law are critical elements influencing the law's effect on health outcomes. Legal practice studies explore these influences as mediators of the statute's or regulation's impact on health.

The core of PHLR involves study of the effects of the law on environments and health behaviours. Laws and their implementation affect social institutions and environments by creating or reducing opportunities, increasing or decreasing available resources, expanding or reducing rights and obligations and creating incentives and penalties. Research in this area examines processes and how they shape the conditions for people to be healthy. Law may affect health behaviours both directly and by shifting the environmental conditions that make particular behavioural choices more or less attractive. For example, drink-driving laws may directly influence driver behaviour through fear of punishment, but also indirectly through the social environment by changing attitudes towards the behaviour. Ultimately, changes in environments and behaviours lead to changes in population-level injury and death. 


\section{Measuring and monitoring law}

When law is being evaluated in quantitative research, the very first methods question is how to capture the attributes of law in a way that will be accepted as reliable by the scientific community. In any study involving laws in multiple jurisdictions that vary across time (for example, studies of state/provincial laws or cross-national studies), accurate measurement of law allows the research to fully exploit the natural experiment that such variation creates. For decades, a small cadre of scientists, including lawyers, has been creating scientifically reliable legal datasets, but there was until recently little in the literature in the way of articulated, shared standards cutting across topical silos. In the past few years, however, both new methods papers (Anderson et al. 2013) and new tools (Public Health Law Research Program 2015) have emerged in PHLR to define standards and support more efficient and accurate measurement of the attributes of statutes and regulations.

Measuring law for scientific purposes is quite different from the way lawyers measure law in traditional legal research. Legal research is typically focused on assessing how a rule may be applied to a particular situation, and is typically focused on current law. In contrast, scientific research is focused on measuring underlying dimensions of law whose importance is derived from theory, and relating those dimensions to other phenomena. To meet scientific standards, a dataset must be created through transparent and reproducible methods, which requires an explicit protocol and variables that are sufficiently objective to be consistently measurable by different researchers. Achieving sufficient reliability requires strict quality-control procedures and, typically, redundant research processes using multiple independent coders.

A dataset of US state laws addressing the use of mobile phones by drivers provides an illustration (Ibrahim et al. 2011). The research encompassed all laws directly addressing the use of mobile communications devices by drivers enacted by US states between 1992 and 2010. Given that 39 states had passed more than 300 iterations of these, which were being coded for 20 variables, the project was not small, either in the collection of the law or in its coding.

Both the regulatory strategy and its targets had evolved over the years, which points to the need for both formative research and a recursive approach to coding. Earlier statutes referred to 'cellular telephones' or 
'mobile telephones'. As technology developed, producing more devices capable of being used by a driver to communicate, drafters used broader terms, such as 'mobile communications device', and began to address behaviours such as text messaging. Whether the term 'cell phone' in a traffic law would cover a wi-fi-enabled iPad being used for a Skype call could be quite important for a lawyer applying that law to a particular case, but, for creating legal data, it sufficed to observe that the term 'cell phone' is used to specify the device whose use the law regulates. In addition to the prohibited behaviours, the dataset captured the extensive variation in which categories of drivers were covered, the penalties and the enforcement mechanisms.

Along with a lack of explicit methods guidance, this sort of legal measurement has also been hampered by a lack of tools. Collecting and coding laws on paper are tedious, and require a second data-entry step that costs time and introduces a risk of clerical error. Spreadsheet software is also prone to entry error in datasets with many columns and rows; more importantly, it requires manual merging to collect and compare the work of multiple coders. Commercial database software supports forms that reduce clerical error, but generally does not allow multiple coders to work in the same file. Software for free-coding text is sometimes used, and has the advantage of storing and allowing the coder to see the text on the coding form, but is not optimised for quantitative coding with a predetermined coding scheme. In recent years, at least two web-based solutions have emerged that significantly improve matters. Google Forms allows users to build a coding form that feeds data to a spreadsheet and supports simultaneous and redundant coding work. LawAtlas, developed by the Public Health Law Research Program, was designed for coding and publishing legal data. It allows the creation of custom coding forms, stores the legal texts, allows the coder to code and view the text on the same window and supports simultaneous redundant coding. Data can be downloaded into a spreadsheet.

Scientific research methods and software that supports efficient coding and publication have made possible the ongoing collection, analysis, interpretation and dissemination of information about important public health laws. This practice, which is emerging under the label 'policy surveillance' (Chriqui et al. 2011), efficiently satisfies two basic conditions for the effective use of law and law reform to improve health: the creation of data for evaluation and the rapid dissemination of health policy activities to speed up the diffusion of innovation. 


\section{Interdisciplinary approach to the mechanisms of legal effect}

A scientific approach to understanding how law influences health is crucial to assessing whether it does so. Theoretically grounded research illuminating mechanisms of legal effect is important in several ways for public health law research and practice. Theories of how law influences structures, behaviours and environments are used to define the phenomena to be observed. This enables researchers to properly identify effects to measure: tell us where to look, at what point in time we might expect to see effects, how effects might evolve over time and what sort of intended and unintended effects to look for. Because much PHLR is necessarily observational, data on how law works support causal inference by providing evidence of plausible mechanisms to explain an observed association. Theory also helps unpack a law into regulatory components that may make varying contributions to the overall effect, and helps identify dose-response relationships between specific legal components or dimensions and health-related outcomes. In a similar fashion, this kind of evidence can guide reform and implementation. Assuming confidence that law is causing an effect, research on how it does so provides important guidance on ways to influence the magnitude of the effect, reduce unintended consequences or produce the effect more efficiently. Understanding how law works can also guide legislators and regulators to craft innovative interventions aimed at newly recognised problems (Anderson and Burris 2014).

\section{a) Defining the phenomena to be observed}

Law is just one of many factors in a web of causation that shapes health outcomes. A theory of how law will influence the outcome can be used to generate a causal diagram that depicts the process, and the relation of law to other potential causes (Swanson and Ibrahim 2013). Consider a law aimed at the emerging problem of concussion in youth sports. Between 2009 and 2012, nearly all US states passed similar laws aimed at ensuring that athletes suffering a possible concussion in school sports activities were identified and removed from play pending medical clearance (Harvey 2013). The underlying theory of the 'problem' was that kids were not being identified because athletes, coaches and parents were not able to diagnose possible concussion, were unaware of the serious risks or were unwilling to report because of social norms of 
'playing tough' or enduring injury for the sake of the team. The regulatory intervention based on this analysis was to require education for athletes, coaches and parents, removal from play for possibly concussed athletes for a set period and medical clearance before resuming participation. Generally, these laws did not include regulatory oversight or penalties.

Both socio-legal and behavioural theories can illuminate plausible mechanisms through which the law's approach might work, and guide evaluation of whether it actually does. As is often the case in PHLR, consistent data on the incidence of concussion in the target population are not available, so, in the short and medium terms, other measures of legal impact will be needed - and that is where theory is so valuable.

It is clear that information is the primary mechanism through which this law is intended to change behaviour. The legislation itself sends information about the seriousness of the issue. Its primary requirement is that information be provided to coaches, parents and players. One straightforward thing to measure in evaluating the law is the extent to which substantive knowledge of the risk and the symptoms of concussion grows among the targets. But mere knowledge is not enough to assure that behaviour will change. The law will be optimally effective only if beliefs about the danger, and the norms of sporting behaviour, begin to change. Coaches, parents and teachers must all start to see concussion as a bigger problem, and social norms must emerge that make it unacceptable to ignore possible injuries or to fail to seek immediate medical attention. We can draw on many different kinds of theories to figure out how to measure these normative effects.

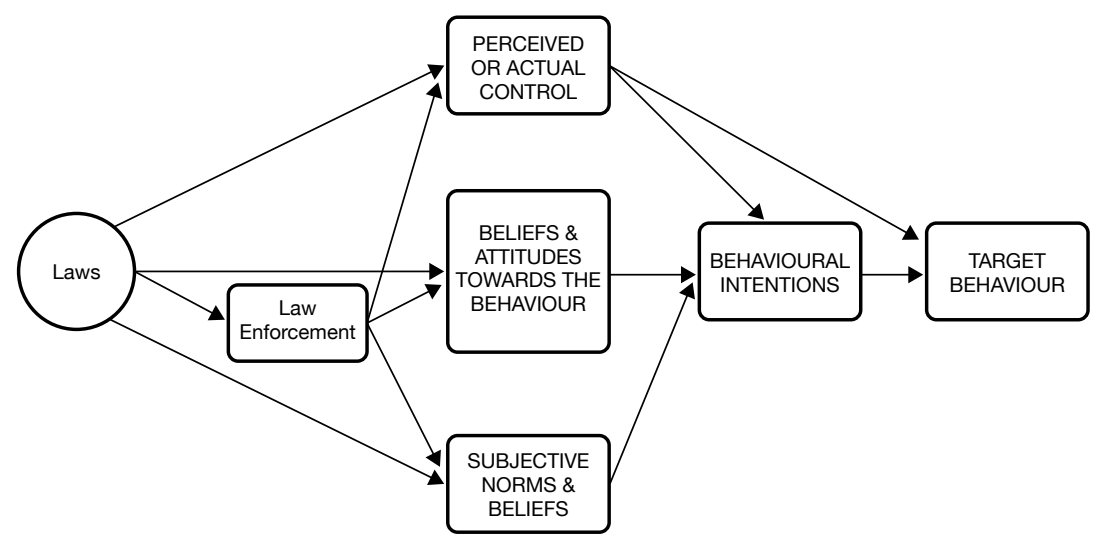

Figure 32.2 Law in the theory of planned behaviour

Source: Author's work. 
The theory of planned behaviour is a widely used tool in social psychology (Ajzen 1991). It explains behaviour in terms of the factors that lead an individual to form an intention to perform the behaviour. A simplified version is applied to the law in Figure 32.2. Behaviour is theorised to be a product of constructs that drive behavioural intent, including attitudes towards the behaviour and its consequences; perceptions of the normative value of performing the behaviour, including perception of how others will view it; and beliefs about the difficulty of performing the behaviour given external or internal constraints. These well-defined constructs can be measured using validated instruments, and can readily be applied to investigate whether a concussion law might be influencing behaviour. Student athletes, for example, could be surveyed over time to determine whether attitudes about concealing a concussion were becoming more negative, whether perceptions about the 'heroism' of such behaviour were changing and whether the law or changing norms were giving them a greater sense of self-efficacy to request medical attention (Register-Mihalik et al. 2013; for further discussion of this kind of theory in PHLR, see Flay and Schure 2013).

Another way to think about measuring the emerging impact of the law is to draw on a theory more familiar to regulatory scholars. Tyler's procedural justice model posits that people are more likely to comply with laws they regard as legitimate and that they have experienced as fairly enforced (see also Murphy, Chapter 3, this volume). Figure 32.3 depicts Tyler's model as it applies to the concussion law, which suggests that compliance with the law can be understood as depending on two related sets of beliefs about the legitimacy of the concussion law and the fairness of its application. We can measure how parents, coaches or students feel about the legitimacy of the legislature issuing mandates about sports; the greater is the legitimacy accorded to the legislature's action, the more likely it is people will feel an obligation to comply as citizens. Likewise, perceptions of procedural fairness in the application of these rules will increase their legitimacy and independently promote compliance. 


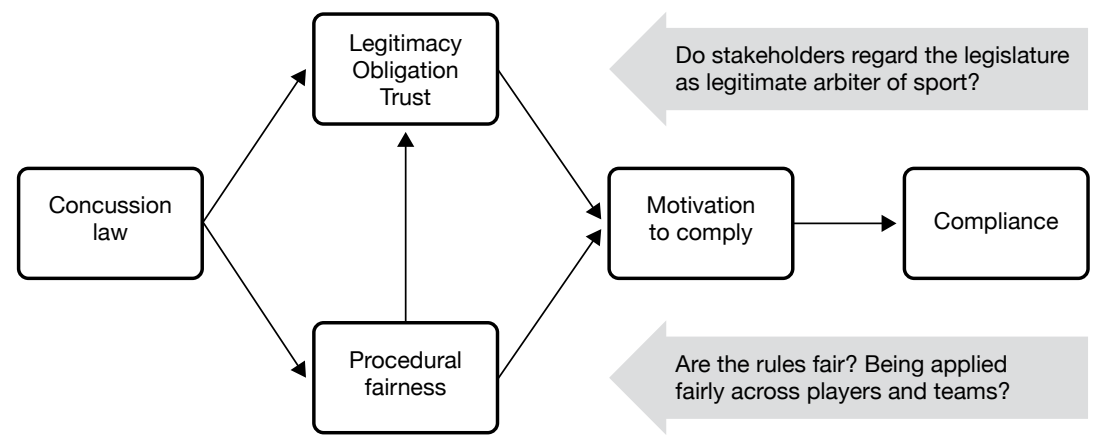

Figure 32.3 Procedural justice and compliance

Source: Author's work.

These theories identify phenomena that can be readily measured to assess whether the law is having any impact, and whether that impact is in the desired direction. They will not tell us whether the law is reducing concussions, but they are relevant to causal inference, as we discuss next.

\section{b) Supporting causal inference}

Like most research on how law influences health, evaluations of the implementation of concussion laws will be observational. They may demonstrate a correlation between the law and a reduction in injury, but have less capacity to support an inference that law caused the outcome. The rate of concussion is caused by many factors, only some of which have been or can be observed. In any sort of study of causation in a complex system, even experimental evidence of causation is bolstered by research that reveals more of the system's elements. Defining the mechanism of effect-an observable, plausible chain of events between the law and the outcome-can help us decide whether an inference of causation is warranted and how confident we should be.

There are many possible explanations for a correlation between a reduction in youth concussions and a law requiring removal from play. The most obvious is that the same community concern about concussion that produced the law has also produced greater awareness of the dangers of traumatic brain injury. Several kinds of research findings could bolster the inference that the law has contributed to the reduction in harm:

- Knowledge of the law influences self-reported compliance or an intention to comply. 
- Knowledge of the law is associated with the belief that playing after a concussion is unwise, that one's peers disapprove of playing after a concussion and that refusing to play (or allow an injured athlete to play) is a feasible behaviour.

- People who know about the law and report compliance or an intention to comply regard the law as legitimate and fairly applied.

If the observed behaviour and attitude in the regulated population are consistent with these hypotheses, and the enactment and implementation of the law are correlated in time with a reduction in harm, we can proceed with more confidence that the law is helping the situation.

\section{c) Guiding reform and implementation}

Having provisional confidence that a law is having an effect on health outcomes is not the end of the inquiry. Logically, we should desire that law has the largest positive effect it can have, with the fewest negative effects. Research that documents the mechanisms of legal effect can make a valuable contribution to making law work better. Documentation of implementation can identify practices that enhance or reduce the law's impact. Negative side effects may be largely the result of how the law is enforced or implemented, rather than an inevitable consequence of the law's terms or design.

In the youth concussion example, early research found that student attitudes towards concussion reporting had the greatest impact on their intention to report (Register-Mihalik et al. 2013). In Washington state, which passed the first of these laws, both athletes and parents are required to review and sign a concussion information form as a condition of participation, but implementation research three years into the regime showed that only 39 per cent of athletes and 58 per cent of parents had completed the form (Chrisman et al. 2014). Other findings indicated that many students were getting limited education from their coaches, but also that how much a coach knew about concussion was not linked with their willingness or ability to identify athletes in their charge who were playing on after suffering one (Rivara et al. 2014). These findings would suggest that greater emphasis on compliance is needed and that, if there are any substantial declines in repeat concussion, it will be difficult to attribute them to the law. Advocates and policymakers can use this information to allocate resources and attention to compliance. 


\section{Study designs}

The objective of PHLR is to improve knowledge of whether a law causes a change in population health. The level of confidence in a causal interpretation of an observed relationship between law and health hinges on the quality of the research design. PHLR is not fundamentally different to other realms of evaluation, but there are some special difficulties and opportunities to address.

The randomised controlled trial (RCT) is routinely referred to as the 'gold standard' for determining whether an intervention caused an effect. Its strength lies in comparing two populations that are identical except for exposure to the intervention. Truly random assignment to treatment and control groups is the essence of the experimental design. Researchers rarely have the opportunity to randomly assign people to be exposed to a law, but some version of that is occasionally possible. The key is usually to cooperate with officials who are keen to learn whether their intervention works. For example, researchers at Temple University cooperated with the Philadelphia Police Department to test the effect of increased foot patrols on violence. The study randomly assigned patrol areas to the treatment (increased foot presence) and control conditions (Ratcliffe et al.2011). Because opportunities for RCTs arise so rarely, it is worthwhile to extract as much value as possible for as long as possible. Between 1994 and 1998, the US Department of Housing and Urban Development randomly assigned clients to two different treatments and a control group to test the impact on poor people of policies that helped them move from high to low-poverty neighbourhoods. Many researchers used the data to test the health and social effects of differing housing support policies over an extended period. For example, a 2011 study reported on health outcomes more than 10 years out (Ludwig et al. 2011).

Another approach is to isolate one element of a policy, or the mechanism of legal effect, for experimental testing. The Behavioural Insights Team of the UK Cabinet Office worked with the Courts Service to test approaches for increasing compliance with fine payment orders. The default treatment was a (costly) bailiff's visit. The experiment tested five different mechanisms of enforcement. One test was a message of some kind versus no message, but the study also used behavioural theory to construct hypotheses about personalised versus non-personalised messages and various forms of personalisation. Two inexpensive trials 
produced the finding that a properly personalised text message could increase payments by $£ 3$ million (AU $\$ 5$ million) and avoid 150,000 bailiff visits annually (Haynes et al. 2012).

While randomised studies could and should be used more in regulatory evaluation, there is a distinguished line of studies in PHLR that takes advantage of the natural experiments that arise when law changes over time or varies across jurisdictions. Indeed, 'effectively combining many design elements into a single study can produce real-world legal evaluations with higher overall levels of validity and strength of causal inference than randomized trials' (Wagenaar and Komro 2013: 309). These elements include many repeated measures; multiple comparison jurisdictions, groups and outcomes; and multilevel structures. Careful attention to theory can also help by identifying the proper time resolution for measuring effects and hypothesising their form. For example, is a new law likely to have an immediate effect at the time its passage is publicised or only after enforcement? Do we expect a drop-off in compliance over time and, if so, how steep?

A classic example of a study taking effective advantage of a natural experiment was conducted by Alexander Wagenaar in the late 1970s (Wagenaar 1981). The US states of Maine and Michigan, which changed the legal age for possession and consumption of alcoholic beverages, were compared with New York state, where the legal age had been 18 for half a century, and Pennsylvania, which had a consistent legal age of twenty-one. This was the first level of comparison. Second, nested within each state, the focal age group affected by the change in law (18-20-year-olds) was compared with younger and older age groups. Third, nested within each age group, alcohol-related car crashes were compared with non-alcoholrelated crashes. Fourth, to address the possibility that changes in the law might be changing the reporting of alcohol involvement, two measures of alcohol-related crashes were observed: normal crash reports by police officers regarding drivers' drinking, and single-vehicle night-time crashes, which were known to have a high probability of involving a drinking driver and which, as a measure, did not rely on officer reports of drinking.

For each cell in this hierarchical design, outcomes were measured monthly for many years before and after the legal changes. There were reductions in crashes beginning in the first month after the new law, but only in the 'experimental' states that raised their legal drinking age (and not in the comparison states), only among teenagers (not among drivers 21 and over, who were not affected by the change in legal age 
from 18 to 21) and only among alcohol-related crashes (and not among non-alcohol-related crashes, measured with two measures of alcoholrelated crashes). These findings supported a highly confident inference that this particular law caused a change in car crashes. Replications in other states that raised the legal age confirmed this pattern of effects.

Public health officials and policymakers considering alternative laws and regulations want to know not only how many disease or injury cases are averted, but also whether it is worth it in terms of the costs involved. Methods for cost-effectiveness and cost-benefit analyses are well described, and there are numerous resources available to assist in building studies (see, generally, Miller and Hendrie 2013). There are, however, some special considerations that arise in designing economic studies of regulatory interventions.

Laws are typically meant to influence behavioural choices. They will require individuals to stop doing things that they enjoy doing, or profit from, on the grounds that these behaviours are deleterious to the common good or, paternalistically, are actually less beneficial than the actor believes. A law requiring motorcyclists to wear a helmet does not just raise the cost of the activity by the price of the helmet; it also deprives the rider of the pleasure of wind blowing through her hair, and reduces her freedom of choice. Costs like these count as social costs. Deciding how to value them can be difficult. It is not just a question of setting an initial price. We know from many instances that regulatory commands initially seen as impositions - such as required safety belt use in vehicles-can become normal behaviours preferred by those who initially resisted them.

Laws are not free to pass, implement or enforce. For example, in 1985, Miller and colleagues estimated the costs of mandating the installation of high-mounted brake lights on cars to reduce rear-end crashes. They specified 15 distinct work tasks, as well as the costs of the administrative notice and comment procedure, and estimated that implementation and administration constituted about 4 per cent of the regulation's total costs (Miller and Hendrie 2013). Health laws may have spillover effects, both positive and negative. Bicycle helmet laws have been found, at least in Australia, to reduce bike use. Motorcycle helmet laws have been observed to reduce motorcycle thefts-presumably, because thieves who happen to be without helmets are deterred from riding without them (Miller and Hendrie 2013). Finally, laws not explicitly aimed at health can nonetheless have important health effects. Income support laws, for example, may have significant effects on the health of children (Komro et al. 2014). 
Finally, qualitative research is a mainstay of regulatory research (see Henne, Chapter 6, this volume). Qualitative research complements quantitative approaches by providing more in-depth or nuanced information on how laws are designed or implemented, and how available health outcome measures might not fully encompass all legal effects. Results from such qualitative studies then feed back into improved measurement and design of quantitative studies. Qualitative research can be used to explore the mechanisms of legal effect suggested by theory, but can also deploy 'grounded theory' methods to inductively develop a theory of legal effect through the research process.

A study by Biradavolu and colleagues (2009) illustrates how standard qualitative research techniques can be used for regulatory research. The research reported was part of an ethnographic study of a sex-worker collective established in a small Indian city to support sex-workers' own efforts to prevent HIV/AIDS. The way police treated sex-workers was an important influence both on their overall quality of life and on their risk for HIV infection. The researchers were interested in whether collectivisation influenced sex-workers' interaction with police. Over time, as part of their overall project, the team learned about interactions with police through interviews with sex-workers, their intimate partners, police, madams, lawyers and clients as well as observation of the collective's activities.

The theme of regulation was an obvious way to think about the function of the police in relation to the sex-workers, and traditional socio-legal theory provided a solid context for understanding the gaps between Indian law on the books and the actual 'law on the street' imposed by police officers. Sex work itself is not illegal in India, and sex-workers have civil rights, but, in practice, police extorted bribes, delivered beatings and arrested sexworkers on other charges. The primary object of this study, however, was to learn more about sex-worker agency. The study explored how sex-workers regulate police, framing their analysis within a definition of regulation as any process or set of processes by which norms are established, the behavior of those subject to the norms monitored or fed back into the regime, and for which there are mechanisms for holding the behavior of regulated actors within the acceptable limits of the regime (whether by enforcement action or by some other mechanism). (Scott 2001:283)

The study revealed that the sex-workers, through their collective, were able to build an effective regulatory pyramid. The collective educated the police and the public about their rights and the role of sex-workers 
in preventing HIV. Along with information, they deployed deterrence: sex-workers began to assert their rights vocally when threatened with unjustified arrest. If that failed, sanctions escalated and networked sexworkers quickly reported arrests to the collective, which responded by sending representatives to the police station to intervene:

For especially egregious abuses, such as physical assault ... written complaints were filed with superior officers and more nodes of the network, such as the media or political groups, were tapped into to put pressure on the police. At the peak of the pyramid was ... challenging police abuse in the courts. (Biradavolu et al. 2009: 6)

\section{Conclusion}

It is universally accepted that a drug should not be used on patients until it has been tested and found to be both safe and effective. Laws, by contrast, are commonly applied in large doses to millions of citizens without any testing whatsoever. This has something to do with the difference between pharmaceuticals and regulations, but a point remains: public health laws are treatments and it is important to know whether they work, and with what side effects. Public health law research is the field devoted to this inquiry, drawing on a wide range of behavioural theories and research methods.

\section{Further reading}

Burris, S and Anderson, E 2013. 'Legal regulation of health-related behavior: A half century of public health law research', Annual Review of Law and Social Science 9: 95-117. doi.org/10.1146/ annurev-lawsocsci-102612-134011.

Epstein, L and King, G 2002. 'The rules of inference', University of Chicago Law Review 69(1): 1-133. doi.org/10.2307/1600349.

\section{References}

Ajzen, I 1991. 'The theory of planned behavior', Organizational Behavior and Human Decision Processes 50(2): 179-211. doi.org/10.1016/07495978(91)90020-T. 
Anderson, E and Burris, S 2014. Educated guessing: Getting researchers and research knowledge into policy innovation, A Theory, Practice and Evidence Paper for the Public Health Law Research Program, Temple University Beasley School of Law, Philadelphia.

Anderson, E, Tremper, C, Thomas, S and Wagenaar, A 2013. 'Measuring statutory law and regulations for empirical research', in A Wagenaar and S Burris (eds), Public Health Law Research: Theory and Methods. San Francisco: John Wiley \& Sons, pp. 237-60.

Berkman, L and Kawachi, I 2000. Social Epidemiology. New York: Oxford University Press.

Biradavolu, MR, Burris, S, George, A,Jena, A and Blankenship, KM 2009. 'Can sex workers regulate police? Learning from an HIV prevention project for sex workers in southern India', Social Science and Medicine 68(8): 1541-7. doi.org/10.1016/j. socscimed.2009.01.040.

Braithwaite, J, Coglianese, C and Levi-Faur, D 2007. 'Can regulation and governance make a difference?', Regulation and Governance 1(1): 1-7. doi.org/10.1111/j.1748-5991.2007.00006.x.

Burris, S, Ashe, M, Levin, D, Penn, M and Larkin, M 2016. 'A transdisciplinary approach to public health law: The emerging practice of legal epidemiology', Annual Review of Public Health 37(1): 135-48. doi.org/10.1146/annurev-publhealth-032315-021841.

Burris, S, Wagenaar, AC, Swanson, J, Ibrahim, JK and Mellow, MM 2010. 'Making the case for laws that improve health: A framework for public health law research', Milbank Quarterly 88(2): 169-210. doi.org/10.1111/j.1468-0009.2010.00595.x.

Chriqui, JF, O'Connor, JC and Chaloupka, FJ 2011. 'What gets measured, gets changed: Evaluating law and policy for maximum impact', Journal of Law, Medicine E' Ethics 39(Supp. 1): 21-6. doi. org/10.1111/j.1748-720X.2011.00559.x.

Chrisman, SP, Schiff, MA, Chung, SK, Herring, SA and Rivara, FP 2014. 'Implementation of concussion legislation and extent of concussion education for athletes, parents, and coaches in Washington state', American Journal of Sports Medicine 42(5): 1190-6. doi.org/10.1177/0363546513519073. 
Commission on Social Determinants of Health (CSDH) 2008. Closing the Gap in a Generation: Health Equity through Action on the Social Determinants of Health. Geneva: World Health Organization.

Flay, BR and Schure, MB 2013. 'The theory of triadic influence', in A Wagenaar and S Burris (eds), Public Health Law Research: Theory and Methods. San Francisco: John Wiley \& Sons, pp. 169-92.

Harvey, HH 2013. 'Reducing traumatic brain injuries in youth sports: Youth sports traumatic brain injury state laws, January 2009 December 2012', American Journal of Public Health 103(7): 1249-54. doi.org/10.2105/AJPH.2012.301107.

Haynes, L, Service, O, Goldacre, B and Torgerson, D 2012. Test, Learn, Adapt: Developing Public Policy with Randomised Controlled Trials. London: Cabinet Office Behavioural Insights Team.

Ibrahim, JK, Anderson, ED, Burris, SC and Wagenaar, AC 2011. 'State laws restricting driver use of mobile communications devices: "Distracted-driving" provisions, 1992-2010', American Journal of Preventative Medicine 40(6): 659-65. doi.org/10.1016/j. amepre.2011.02.024.

Komro, KA, Burris, S and Wagenaar, AC 2014. 'Social determinants of child health: Concepts and measures for future research', Health Behavior and Policy Review 1(6): 432-45. doi.org/10.14485/ HBPR.1.6.1.

Ludwig, J, Sanbonmatsu, L, Gennetian, L, Adam, E, Duncan, GJ, Katz, LF, Kessler, RC, Kling, JR, Lindau, ST, Whitaker, RC and McDade, TW 2011. 'Neighborhoods, obesity, and diabetes: A randomized social experiment', New England Journal of Medicine 365: 1509-19. doi.org/10.1056/NEJMsa1103216.

Miller, TR and Hendrie, D 2013. 'Cost-effectiveness and cost-benefit analysis of public health laws', in A Wagenaar and S Burris (eds), Public Health Law Research: Theory and Methods. San Francisco: John Wiley \& Sons, pp. 347-78.

Public Health Law Research Program 2015. Law Atlas: The Policy Surveillance Portal. Philadelphia: Temple University. Available at: LawAtlas.org. 
Ratcliffe, JH, Taniguchi, T, Groff, ER and Wood, JD 2011. 'The Philadelphia foot patrol experiment: A randomized controlled trial of police patrol effectiveness in violent crime hotspots', Criminology 49(3): 795-831. doi.org/10.1111/j.1745-9125.2011.00240.x.

Register-Mihalik, JK, Linnan, LA, Marshall, SW, McLeod, TCV, Meuller, FO and Guskiewicz, KM 2013. 'Using theory to understand high school aged athletes' intentions to report sportrelated concussion: Implications for concussion education initiatives', Brain Injury 27(7-8): 878-86. doi.org/10.3109/026990 52.2013.775508.

Rivara, FP, Schiff, MA, Chrisman, SP, Chung, SK, Ellenbogen, RG and Herring, SA 2014. 'The effect of coach education on reporting of concussions among high school athletes after passage of a concussion law', American Journal of Sports Medicine 42(5): 1197-203. doi.org/10.1177/0363546514521774.

Sarat, A 1990. “... the law is all over”: Power, resistance and the legal consciousness of the welfare poor', Yale Journal of Law and the Humanities 2(2): 343-79.

Scott, C 2001. 'Analysing regulatory space: Fragmented resources and institutional design', Public Law (Summer): 329-53.

Stryker, R 2013. 'Law and society approaches', in A Wagenaar and S Burris (eds), Public Health Law Research: Theory and Methods. San Francisco: John Wiley \& Sons, pp. 87-108.

Swanson, J and Ibrahim, J 2013. 'Picturing public health law research: Using causal diagrams to model and test theory', in A Wagenaar and S Burris (eds), Public Health Law Research: Theory and Methods. San Francisco: John Wiley \& Sons, pp. 217-36.

Wagenaar, AC 1981. 'Effects of an increase in the legal minimum drinking age', Journal of Public Health Policy 2(3): 206-25. doi.org/ $10.2307 / 3342367$.

Wagenaar, AC and Komro, KA 2013. 'Natural experiments: Research design elements for optimal causal inference without randomization', in A Wagenaar and S Burris (eds), Public Health Law Research: Theory and Methods. San Francisco: John Wiley \& Sons, pp. 307-24. 
This text is taken from Regulatory Theory: Foundations and applications, edited by Peter Drahos, published 2017 by ANU Press, The Australian National University, Canberra, Australia. 